\title{
Minocycline hydrochloride nanoliposomes inhibit the production of TNF- $\alpha$ in LPS-stimulated macrophages
}

D Liu

P S Yang

Shandong Provincial Key Laboratory of Oral Biomedicine, College of Stomatology, Shandong University, Shandong Province, People's Republic of China
This article was published in the following Dove Press journal:

International Journal of Nanomedicine

30 August 2012

Number of times this article has been viewed

Background: As an adjunctive treatment of chronic periodontitis, it seems that the application of periocline or the other antimicrobials is effective against periodontopathogens. In this study, nanoliposomes were investigated as carriers of minocycline hydrochloride and the inhibition effects of minocycline hydrochloride nanoliposomes on the proliferation and lipopolysaccharide (LPS)-stimulated production of tumor necrosis factor- $\alpha$ (TNF- $\alpha$ ) of macrophages were elucidated.

Methods: After stimulation with $10 \mu \mathrm{g} / \mathrm{mL}$ LPS, murine macrophages (ANA-1) were treated with $10,20,40,50$ and $70 \mu \mathrm{g} / \mathrm{mL} 2 \%$ minocycline hydrochloride nanoliposomes, minocycline hydrochloride solution, and periocline for 6, 12, 24, 48 and 60 hours, respectively. A tetrazolium (MTT) assay was used to evaluate macrophages cell proliferation rate and the levels of TNF- $\alpha$ mRNA were measured by SYBR Green Real Time PCR.

Results: Ten to $70 \mu \mathrm{g} / \mathrm{mL} 2 \%$ minocycline hydrochloride nanoliposomes, minocycline hydrochloride solution, and periocline showed dose- and time-dependent inhibition of ANA-1 proliferation. Minocycline hydrochloride nanoliposomes showed dose- and ratio-dependent inhibition of LPS-stimulated TNF- $\alpha$ secretion of ANA-1. The inhibition effect of $10 \mu \mathrm{g} / \mathrm{mL}$ minocycline hydrochloride nanoliposomes was significantly better than that of two positive control groups, and equated to that of 60 or $70 \mu \mathrm{g} / \mathrm{mL}$ periocline. The expression of TNF- $\alpha$ mRNA in experimental group continued to reduce linearly with time.

Conclusion: All three preparations of minocycline hydrochloride showed dose- and timedependent inhibition of proliferation of ANA-1. Minocycline hydrochloride nanoliposomes have stronger and longer inhibition effect on LPS-stimulated TNF- $\alpha$ secretion of macrophages cell than minocycline hydrochloride solution and periocline.

Keywords: minocycline hydrochloride, nanoliposomes, periodontitis, lipopolysaccharide, macrophages, tumor necrosis factor- $\alpha$

\section{Introduction}

Periodontitis is a chronic inflammatory disease, which results in the destruction of periodontal connective tissue, alveolar bone resorption, and tooth loss. ${ }^{1,2}$ Lipopolysaccharide (LPS) leads to chronic inflammation resulting in disruption of the structural integrity of the periodontal ligament and progressive alveolar bone destruction. The infected/inflamed area in periodontitis was shown to be associated with macrophage activation via increased serum LPS. ${ }^{3}$ LPS can directly activate macrophages and participate in the pathogenesis of various periodontal diseases through expression of a host of proinflammatory factors. Among them, tumor necrosis factor- $\alpha$ (TNF- $\alpha$ ) is thought to be pivotal cytokine in the context of periodontal disease. ${ }^{4,5}$ 
As an adjunctive treatment of chronic periodontitis, it seems that the systemic of local application of antimicrobials is effective against periodontopathogens, and it can reduce the pocket depth, and hopefully it can need for surgery. ${ }^{6-8}$ Minocycline hydrochloride, a broad-spectrum antibiotic was found to have a potential anti-inflammatory efficacy in periodontitis. The systemic administration of minocycline hydrochloride has been demonstrated as having a long-term reductive effect on subgingival microorganisms. ${ }^{9}$ It has also been proved to play a role in the immune response caused by cell factors with beneficial effect on various indices of periodontal health. ${ }^{10}$

Various types of nanoliposomes are currently used clinically as delivery systems for drugs. The nanoliposomal system is highly desirable for drug delivery due to the following advantages. Firstly, it is relative easy to incorporate hydrophilic and lipophilic therapeutic agents in liposomes. Secondly, liposomes can be delivered directly to an accessible body site, such as the periodontium. Thirdly, the nanoliposomes are relative nonimmunogenicity and low toxicity. ${ }^{11-13}$ Nanoliposomes also have a natural targeting for macrophages. Minocycline hydrochloride cannot readily pass through the lipids because of their relatively hydrophilic. The local application, when associated with a controlled release and targeted drug-delivery device, offers the advantage of containing the high concentration of the drug in the pocket. This reduces the risk of side effects ${ }^{14}$ and of the possible appearance of microbial resistance. ${ }^{15}$

As one of the main pathogenesis of the periodontitis, LPS can directly induce TNF- $\alpha$ release from macrophages. This prompts us to investigate the anti-inflammatory effects of minocycline hydrochloride nanoliposomes in inhibiting inflammatory cytokine TNF- $\alpha$ secretion in a mouse macrophage cell (ANA-1) stimulated by LPS and to determine the mechanism of action in periodontitis treatment.

\section{Materials and methods Materials}

The Centrophase HR/HR-2B was purchased from Central Soya Co (Fort Wayne, IN). The NBD Cholesterol was purchased from Invitrogen, Life Technologies (Carlsbad, CA). M9511 (100 mg) was purchased from SIGMA (St Louis, MO). The thiazolyl blue (BY11088; $250 \mathrm{mg}$ ) was purchased from SIGMA. The lipopolysaccharides (L2880; $10 \mathrm{mg}$ ) obtained from Escherichia coli was purchased from SIGMA. The periocline (JP01021603; $0.5 \mathrm{~g}$ ) was purchased from Sunstar Inc (Osaka, Japan).

\section{Preparation of minocycline hydrochloride nanoliposomes}

Nanoliposomes composed of hydrogenated soy phosphatidylcholine and cholesterol (molar ratio, 2:1) were prepared via extrusion. Lipids were combined in their respective molar ratios and then dissolved in a 9:1 mixture (by volume) of 99.9\% chloroform. The organic solvent was then evaporated under a stream of nitrogen. After an even and uniformly dried lipid film was obtained, the dried lipid layer was hydrated with minocycline hydrochloride solution $(5 \mathrm{mg} / \mathrm{mL})$ and Dulbecco's phosphate-buffered saline (PBS) without calcium chloride and magnesium chloride. The lipid suspension was then mixed for 1-2 minutes on level 5 using a Mini Vortexer mixer (Fisher Scientific, Pittsburg, PA). Unilamellar liposomes were then bathsonicated at room temperature for 20 minutes using a special ultrasonic cleaner, whereas multilamellar liposomes were not immediately sonicated. After stirring, the nanoliposomes had a mean diameter of $90 \pm 15 \mathrm{~nm}$ (Figure $1 \mathrm{~A}$ and $\mathrm{B}$ ).

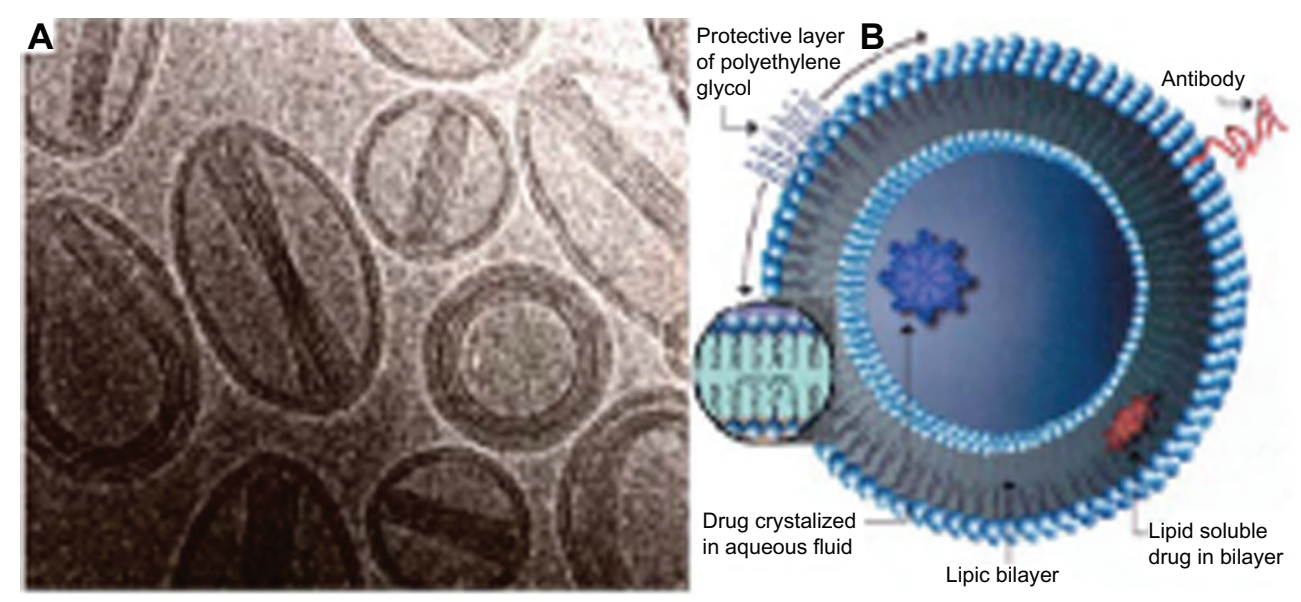

Figure I Scanning electron microscopy images (A) and structure schematic drawing (B) of liposomes. 


\section{MTT assay test macrophages cell proliferation rate}

According to the manufacturer's protocol, ANA-1 cells were seeded in a 96-well plate with $6 \times 10^{3}$ cells per well, and subsequently treated with $10,20,40,50,70$, and $100 \mu \mathrm{g} / \mathrm{mL}$ $2 \%$ minocycline hydrochloride nanoliposomes, periocline, $2 \%$ minocycline hydrochloride solution, and blank group for $1,6,12,18,24,48$, and 60 hours. Thereafter, cell viability was determined by the MTT assay. The cell relative growth rate (RGR) was calculated as following (OD of experimental group/OD of control group) $\times 100 \%$. The ANOVA was used to analyze the RGR differences among three treatment groups. And the multivariation linear regression was used to analyze the influence of concentration (x1) and time (x2) to the cell relative growth rate of $2 \%$ minocycline hydrochloride nanoliposomes, periocline, $2 \%$ minocycline hydrochloride solution, and reciprocal effect $(\mathrm{x} 1 * \mathrm{x} 2)$ between concentration and time. Data were analyzed by SPSS software (SPSS Inc, Chicago, IL).

\section{SYBR Green Real Time PCR (RT-PCR) measure the levels of TNF- $\alpha$ mRNA}

The specimens were divided into five groups at random: bland group; negative control, $10 \mu \mathrm{g} / \mathrm{mL}$ LPS; experimental group, $2 \%$ minocycline hydrochloride nanoliposomes; positive control I, periocline ( $2 \%$ minocycline hydrochloride Gel); positive control II, $2 \%$ minocycline hydrochloride solution. After stimulation with $10 \mu \mathrm{g} / \mathrm{mL}$ LPS for 1 hour, all the ANA-1 cells were treated with $10,20,40,50$, and $70 \mu \mathrm{g} / \mathrm{mL}$
$2 \%$ minocycline hydrochloride nanoliposomes, periocline, and $2 \%$ minocycline hydrochloride solution for 6,12 , 24, 48, 60 hours. Total cellular RNA was extracted by using the Trizol method. The concentration of the RNA was determined by measuring the absorbance at 260 and $280 \mathrm{~nm}$. Total RNA was used as a template for the cDNA synthesis. The reverse transcription (RT) was performed by using ReverTra Ace TM. The primer sequences for PCR amplification were as follows: TNF- $\alpha$, forward primer, 5'-CACGTCGTAGCAAACCACCAA- $3^{\prime}$, and reverse primer, 5'-GTTGGTTGTCTTTGAGATCCAT-3'; 100 bp; Then, $1 \mu \mathrm{L}$ cDNA was amplified by PCR with a Bio-Rad thermal cycler. The PCR products were separated in $1.8 \%$ agarose gel electrophoresis, and visualized by ethidium bromide staining. Data were analyzed by SPSS software (SPSS 12.0; SPSS Inc., Chicago, IL) and analysis of variance.

\section{Results \\ Effects of minocycline hydrochloride nanoliposomes on ANA-I viability}

Three treatment groups including 2\% minocycline hydrochloride nanoliposomes, periocline and 2\% minocycline hydrochloride solution could suppress macrophages proliferation. The results of ANOVA showed that there was no statistically significant difference in the inhibition of macrophages proliferation among these three groups. With extending of treatment time and the increasing concentration, the macrophages cell proliferation rate continued decline (Figure 2).

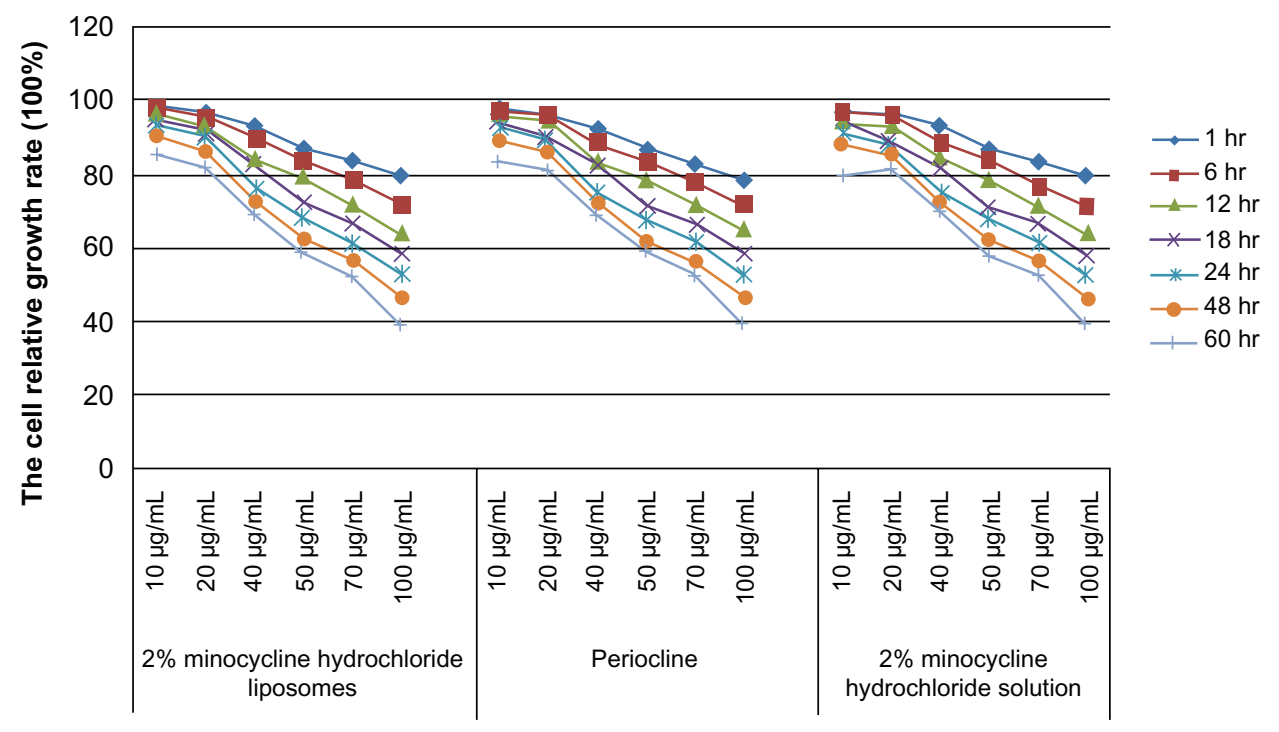

Figure 2 Effects of macrophages proliferation rate of $10-100 \mu \mathrm{g} / \mathrm{mL} 2 \%$ minocycline hydrochloride nanoliposomes, periocline, and $2 \%$ minocycline hydrochloride solution work on ANA-I for I, 6, 12, 18, 24, 48, and 60 hours.

Abbreviations: hr, hours; Periocline, $2 \%$ minocycline hydrochloride gel; ANA-I, murine macrophages (ANA-I). 
Significant negative correlations were observed between the cell relative growth rate and factors of time, concentration of $2 \%$ minocycline hydrochloride nanoliposomes, periocline, $2 \%$ minocycline hydrochloride solution $\left(\mathrm{R}^{2}=0.9473\right.$, $P<0.0001, \mathrm{R}^{2}=0.9468, P<0.0001, \mathrm{R}^{2}=0.9437$, $P<0.0001)$, and moreover there were interactions effects between the factors of time and concentration $(P<0.0001$, $P<0.0001, P<0.0001$ ) (Table 1).

\section{Effects of minocycline hydrochloride nanoliposomes on LPS-induced gene expression of TNF- $\alpha$}

Both $10,20,40,50$, and $70 \mu \mathrm{g} / \mathrm{mL} 2 \%$ minocycline hydrochloride nanoliposomes and 20, 40, 50, and $70 \mu \mathrm{g} / \mathrm{mL}$ periocline, $2 \%$ minocycline hydrochloride solution showed dose- and time-dependent reduction of LPS-induced TNF- $\alpha$ mRNA expression on macrophages compared with LPS treated groups $(P<0.05)$. But $10 \mu \mathrm{g} / \mathrm{mL} 2 \%$ minocycline hydrochloride solution and periocline did not generate any inhibitions to TNF- $\alpha$ as $10 \mu \mathrm{g} / \mathrm{mL}$ nanoliposomes did (Figure 3A). The inhibitions of $10-70 \mu \mathrm{g} / \mathrm{mL} 2 \%$ minocycline hydrochloride nanoliposomes on TNF- $\alpha$ secretion were stronger than both positive groups (Figure $3 \mathrm{~A}-\mathrm{E}$ ), and the inhibitory effects of positive I were better than positive II (Figure $3 \mathrm{~B}-\mathrm{E})(P<0.05)$. The inhibition of $10 \mu \mathrm{g} / \mathrm{mL}$ minocycline hydrochloride nanoliposomes was equated to the effects of 60 or $70 \mu \mathrm{g} / \mathrm{mL}$ periocline (Figure 3A, D and E). And the expression of TNF- $\alpha$ mRNA continued to decrease in proportion, which indicated that minocycline hydrochloride nanoliposomes had the character of controlled release. The inhibitions of periocline on the expression of TNF- $\alpha$ mRNA were increased in 24 hours and decreased in 48 hours. The expression of TNF- $\alpha$ mRNA in $2 \%$ minocycline hydrochloride solution group showed the continuous decrease, and it showed the lowest inhibitory action among the three groups (Figure 3B-E).

\section{Discussion}

Periodontitis commonly is a chronic inflammatory condition in humans. Some studies provided insight that LPS could contribute to defective periodontium in periodontitis. ${ }^{16,17}$ LPS is the leading stimulus that initiates the host response in the periodontal pocket and activates macrophages cells to release proinflammatory cytokines. ${ }^{18-21}$ Consequently, this proinflammatory cytokine can lead to inflammatory cascades and result in periodontium destruction. So the extent of affected tissue in periodontitis is directly associated with the production of cytokines. For an important role in host defense reactions and in homeostasis, local macrophage activation plays a crucial role in periodontium inflammatory process. TNF- $\alpha$ originates mainly from activated macrophages release; it is expressed in higher levels in the gingival crevicular fluid and inflamed periodontium of patients with clinical periodontium disease than in healthy people, and it also causes alveolar bone resorption. ${ }^{22}$

As a conventional anti-inflammatory agent, minocycline hydrochloride exerts anti-inflammatory activity in macrophages and other immune cells, and these effects were independent of its antimicrobial action. It had been demonstrated having a long-term reductive effect on subgingival microorganisms, which was one of its main purposes in the course of periodontitis treatment. Minocycline hydrochloride exhibited strong inhibitory activities against Porphyromonas gingivalis with a minimal inhibitory concentration at $90 \%$ $\left(\mathrm{MIC}_{90}\right)$ less than $0.1 \mu \mathrm{g} / \mathrm{mL}$. For $P$. intermedius and Eikenella eorrodens the $\mathrm{MIC}_{90}$ was less than $0.39 \mu \mathrm{g} / \mathrm{mL}$, while for Fusobacterium nucleatum this was $0.78 \mu \mathrm{g} / \mathrm{mL}{ }^{23}$ Then $10-70 \mu \mathrm{g} / \mathrm{mL}$ minocycline hydrochloride used in this

Table I The influence of factors of time and concentration work on the cell relative growth rate of $2 \%$ minocycline hydrochloride nanoliposomes, periocline, and $2 \%$ minocycline hydrochloride solution

\begin{tabular}{|c|c|c|c|c|c|c|}
\hline & Variable & DF & Parameter estimate & Standard error & $t$ value & $\operatorname{Pr}>|\mathbf{t}|$ \\
\hline $2 \%$ minocycline hydrochloride & $x \mid$ & 1 & -0.29896 & 0.02949 & -10.14 & $<0.0001$ \\
\hline \multirow[t]{2}{*}{ nanoliposomes } & $\times 2$ & 1 & -0.17686 & 0.05322 & -3.32 & $<0.0002$ \\
\hline & $x 1^{*} x 2$ & I & -0.00454 & 0.00093356 & -4.87 & $<0.0001$ \\
\hline \multirow[t]{3}{*}{ Periocline } & $x \mid$ & 1 & -0.29928 & 0.02930 & -10.22 & $<0.0001$ \\
\hline & $x 2$ & 1 & $-0 .|957|$ & 0.05287 & -3.70 & $<0.0007$ \\
\hline & $x 1^{*} x 2$ & 1 & -0.00423 & 0.00092739 & -4.56 & $<0.0001$ \\
\hline $2 \%$ minocycline hydrochloride & $x \mid$ & 1 & -0.29288 & 0.02967 & -9.87 & $<0.0001$ \\
\hline \multirow[t]{2}{*}{ solution } & $x 2$ & 1 & -0.20907 & 0.05355 & -3.90 & $<0.0004$ \\
\hline & $\left.x\right|^{*} x 2$ & 1 & -0.00404 & 0.00093938 & -4.30 & $<0.0001$ \\
\hline
\end{tabular}

Notes: $\mathrm{xI}, 10,20,40,50,70$ and $100 \mu \mathrm{g} / \mathrm{mL} ; \times 2,1,6,12,18,24,48$, and 60 hours; $\times 1 * x 2$, reciprocal effect between concentration and time factors. Abbreviations: Periocline, $2 \%$ minocycline hydrochloride gel; DF, degree of freedom. 

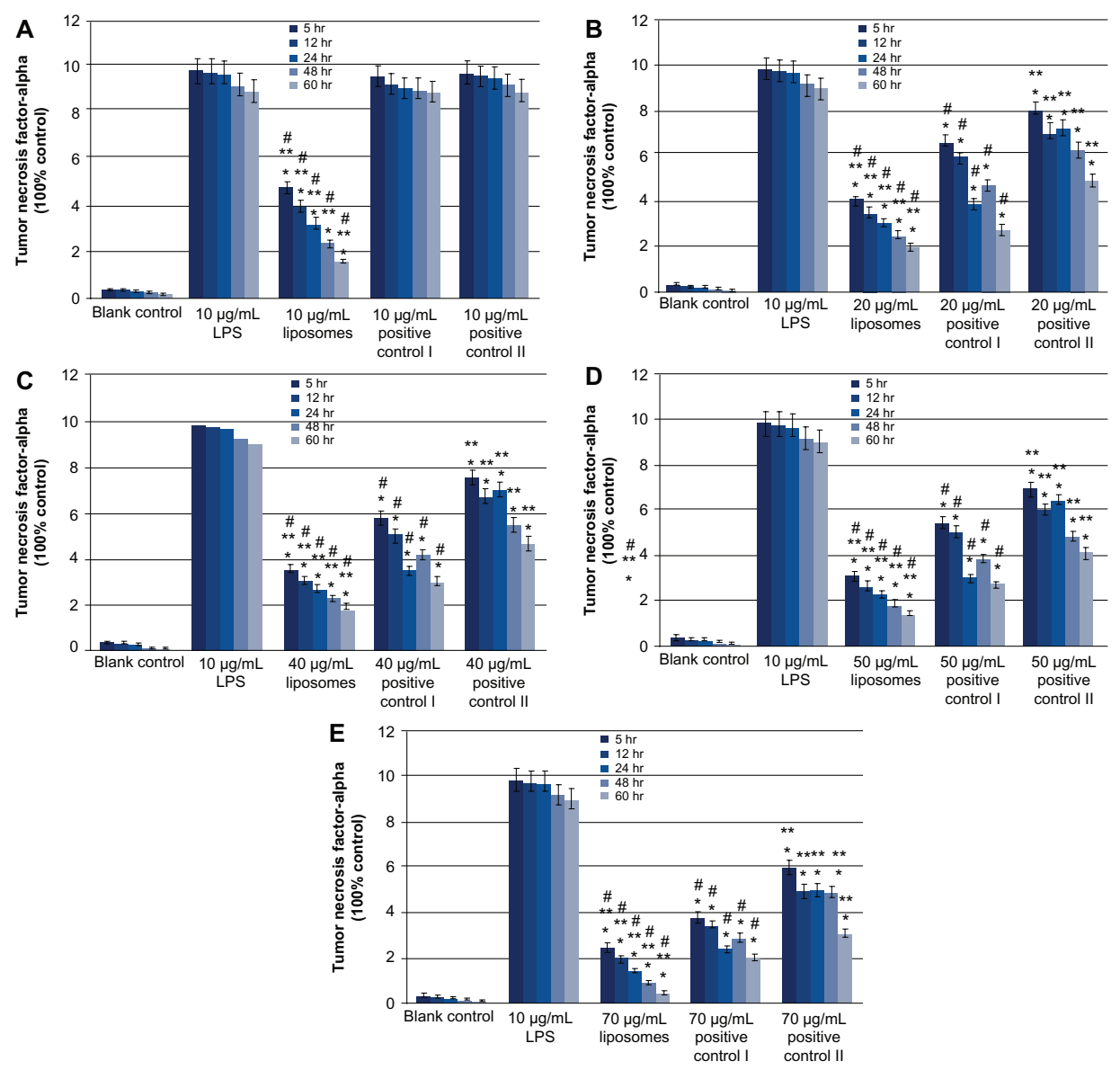

Figure 3 Quantitative analysis of RT-PCR products of TNF- $\alpha$ mRNA at 6 hours, 12 hours, 24 hours, 48 hours and 60 hours; values are means \pm SD from three duplicate experiments. ${ }^{*} P<0.05$, different from the value in LPS treated groups; ${ }^{* * P}<0.05$, different from the value in periocline-treated groups; ${ }^{*} P<0.05$, different from the value in $2 \%$ minocycline hydrochloride solution treated groups. Drug concentration of experimental group, positive control I and positive control II were I0 (A), 20 (B), 40 (C), 50 (D) and 70 (E) $\mu \mathrm{g} / \mathrm{mL}$ respectively.

Abbreviations: Periocline, $2 \%$ minocycline hydrochloride gel; RT-PCR, Reverse Transcription-Polymerase Chain Reaction; TNF- $\alpha$, Tumor necrosis factor-alpha; LPS, Lipopolysaccharide; SD, standard deviation.

study, theoretically not only can contribute to antibacterial requirements, but also have an effect on immune response.

Minocycline hydrochloride have been proved to exhibit anti-inflammatory action by inhibiting macrophages. ${ }^{24}$ Our research verified that $2 \%$ minocycline hydrochloride nanoliposomes, $2 \%$ minocycline hydrochloride solution, and periocline all showed inhibition of macrophage proliferation, and there were no statistical difference among them. This inhibition effect was positively correlated with time and concentration of the drugs. Positive control I, periocline, is a topical antibiotic approved in a number of countries, and is a slow-release drug that has been proved to be effective and widely used in clinical topical periodontitis treatment. ${ }^{25}$ Moreover, our results showed that treatment of macrophages with $20-70 \mu \mathrm{g} / \mathrm{mL} 2 \%$ minocycline hydrochloride solution, periocline and $10-70 \mu \mathrm{g} / \mathrm{mL} 2 \%$ minocycline hydrochloride nanoliposomes could significantly suppress LPS-induced TNF- $\alpha$ production time and dose-dependently. The key point of this study was that $2 \%$ minocycline hydrochloride nanoliposomes had significantly stronger and longer inhibition effect on LPS-stimulated TNF- $\alpha$ secretion of macrophages cell than periocline and minocycline hydrochloride solution, which will contribute to reducing the impact of cytokinemediated tissue destructive processes in periodontitis more efficiently. This result indicated that nanoliposomes were a new way with a greater efficiency of anti-inflammatory action in the low dose $(10 \mu \mathrm{g} / \mathrm{mL})$. The reasons were as follow: ${ }^{26-29}$ (1) Liposome drug delivery seeks to concentrate the medication in the tissues of interest while reducing the relative concentration of the medication in the remaining tissues. This improved efficacy can reduce side effects; (2) Suspensions of liposomes with diameter of $130 \pm 15 \mathrm{~nm}$ are possible since the interaction of the particle surface with the solvent is strong enough to overcome density differences. Nanoliposomes have a very high surface area to volume ratio, which provides a tremendous driving force for diffusion, and have excellent 
moisturizing and penetrating properties; (3) Liposomes are composed of naturally occurring, biodegradable lipids organized into bilayer lipid membranes that enclose an aqueous core. Due to their unique properties, nanoliposomes can carry both hydrophobic molecules and hydrophilic molecules to deliver the molecules to sites of action. The nanoliposomes encapsulate a region on minocycline hydrochloride aqueous solution inside a hydrophobic membrane; dissolved hydrophilic minocycline hydrochloride cannot readily pass through the lipids. The lipid bilayer can fuse with the bilayer of cell membrane, and then carry minocycline hydrochloride into macrophages directly; (4) Liposomes can deliver the drug to sites of abundant macrophages for their specificity for macrophages. They can be made in a particular size (90 $\pm 15 \mathrm{~nm}$ ) which makes them viable targets for natural macrophage phagocytosis. Macrophages may be responsible for the phagocytosis of targeting device liposomes. Then liposome-encapsulated drugs can slowly emanate to inhibit their production and release of proinflammatory cytokines, which seems to be responsible for reducing inflammatory reactions during periodontitis. Encapsulation of minocycline hydrochloride within nanoliposomes can greatly increase their intracellular delivery to specific target cells, enhance their protective effects against intracellular oxidant-mediated damage, and extend biologic half-life of minocycline hydrochloride.

Results also found that the expression of TNF- $\alpha$ mRNA continued to decrease in proportion in experimental group, which suggested $2 \%$ minocycline hydrochloride nanoliposomes might have a controlled release role. The inhibition of periocline showed nonregularity and reduction in volatility as slow release systems did. The controlled release systems can protect the supply of the agent to allow the automatic release of the agent to the target at a controlled rate and to maintain its concentration in the system within the optimum limits over a specified period of time, thereby providing great specificity and persistence without diminishing efficiency. ${ }^{30,31}$ Controlled release of minocycline hydrochloride could be used to maintain the local concentration of active ingredients in the periodontium and to reduce runoff. ${ }^{32,33}$

The improvements of minocycline hydrochloride liposome are: (1) Specificity for macrophages, which is obtained by phagocytosis of liposomes. (2) Organ or tissue specificity, which is obtained by using different administration routes. (3) Actions should be unidirectional: high and low doses should not have opposite effects. (4) It is harmless and biodegradable of both carriers and drugs. (5) Activity can last for a defined periodontitis of time only.
(6) It avoids the release of dead-cell remnants and products. (7) It is specifically concern either phagocytosis or cyto/ chemokine production.

However, the size of liposomes and their stability by interaction with serum proteins were considered to be major problems. In this vitro study, the stability of these liposomes after 24 hours incubation was unclear. In the preliminary study, the encapsulation efficiency was approximately $70 \%$ after 24 hours incubation in the medium. We used the heat-inactivated fetal bovine serum in this study and the contributions of the factors that influence the instability of liposomes were considered to be low. Generally, the administered liposomes were eliminated from the circulation due to the increased instability of them following the interaction with serum proteins and to the uptake of them by reticuloendothelial system (RES) and/or mononuclear phagocyte system (MPS). ${ }^{34}$ Moreover, the instability and in vivo behavior of liposomes were closely related to their size. The larger size liposomes showed higher instability and higher uptake by the RES and/or MPS. Application of small unilamellar vesicles modified with polyethylene glycol (PEG) might solve these problems. ${ }^{35}$ Further studies are necessary to examine the anti-inflammatory effects of minocycline hydrochloride liposome by a series of in vivo experiments.

\section{Conclusion}

The preparation of minocycline hydrochloride nanoliposomes can inhibit the proliferation of murine macrophages (ANA-1), and specifically achieve the stronger anti-inflammatory effects by suppression of TNF- $\alpha$ mRNA expression. And it will be a more effective potential therapeutic agent for inflammatory and immune periodontal diseases with a reduced dose $(10 \mu \mathrm{g} / \mathrm{mL})$. The controlled release effects of minocycline hydrochloride nanoliposomes could provide a long-term therapeutic effect of drug at the site of action following a single dose. The minocycline hydrochloride nanoliposomes show a promising potential for targeted, controlled release topical periodontitis therapy.

\section{Acknowledgments}

This work was partially supported by West China School of Pharmacy, Sichuan University for preparation and quality assessment of minocycline hydrochloride nanoliposomes.

\section{Disclosure}

The authors declare that there are no conflicts of interests in this study. 


\section{References}

1. Socransky S, Haffajee A. Evidence of bacterial aetiology: a historical perspective. Periodontol 2000. 1994;5:7-25.

2. Armitage GC. Development of a classification system for periodontal diseases and conditions. Ann Periodontol. 1999;4:1-6.

3. Pussinen PJ, Vilkuna-Rautiainen T, Alfthan G, et al. Severe periodontitis enhances macrophage activation via increased serum lipopolysaccharide. Arterioscler Thromb Vasc Biol. 2004;24:2174-2180.

4. Li L, Khansari A, Shapira L, et al. Contribution of interleukin-11 and prostaglandin(s) in lipopolysaccharide-induced bone resorption in vivo. Infect Immun. 2002;70:3915-3922.

5. Chiang CY, Kyritsis G, Graves DT, et al. Interleukin-1 and tumor necrosis factor activities partially account for calvarial bone resorption induced by local injection of lipopolysaccharide. Infect Immun. 1999;67: 4231-4236.

6. Page RC. The microbiological case for adjunctive therapy for periodontitis. J Int Acad Periodontol. 2004;6:143-149.

7. Zhao N, Ge SH, Ding GY. Clinical effect of minocycline as adjunctive therapy to scaling and root planning on treatment of chronic periodontitis. Hua Xi Kou Qiang Yi Xue Za Zhi. 2006;24:32-35.

8. Cortelli JR, Querido SM, Aquino DR, et al. Longitudinal clinical evaluation of adjunct minocycline in the treatment of chronic periodontitis. J Periodontol. 2006;77:161-166.

9. Paquette DW, Ryan ME, Wilder RS. Locally delivered antimicrobials: clinical evidence and relevance. J Dent Hyg. 2008;3:10-15.

10. Gopinath V, Ramakrishnan T, Emmadi P, et al. Effect of a controlled release device containing minocycline microspheres on the treatment of chronic periodontitis: A comparative study. J Indian Soc Periodontol. 2009;13:79-84.

11. Suntres ZE, Shek PN. Prophylaxis against lipopolysaccharide-induced lung injuries by liposome-entrapped dexamethasone in rats. Biochem Pharmacol. 2000;59:1155-1161.

12. Ratnam DV. Role of antioxidants in prophylaxis and therapy: a pharmaceutical perspective. J Control Release. 2006;113:189-207.

13. Osawa M, Anderson DE, Erickson HP. Reconstitution of contractile FtsZ Rings in liposomes. Science. 2008;9:792-794.

14. Pascale D, Gordon I, Lamster I, et al. Concentration of doxycycline in human gingival fluid. J Clin Periodontol. 1986;13:841-844.

15. Walters JD, Nakkula RJ, Maney P. Modulation of gingival fibroblast minocycline accumulation by biological mediators. J Dent Res. 2005;84:320-323.

16. Park SY, Park DJ, Kim YH, et al. Schisandra chinensis $\alpha$-iso-cubebenol induces heme oxygenase-1 expression through PI3K/Akt and Nrf2 signaling and has anti-inflammatory activity in Porphyromonas gingivalis lipopolysaccharide-stimulated macrophages. Int Immunopharmacol. 2011;11:1907-1915.

17. Larsen T. Occurrence of doxycycline resistant bacteria in the oral cavity after local administration of doxycycline in patients with periodontal disease. Scand J Infect Dis. 1991;23:89-95.

18. Roberts FA, Hockett RD, Bucy RP, et al. Quantitative assessment of inflammatory cytokine gene expression in chronic adult periodontitis. Oral Microbiol Immunol. 1997;12:336-344.
19. Gamonal J, Acevedo A, Bascones A, et al. Levels of interleukin-1 beta, -8 , and -10 and RANTES in gingival crevicular fluid and cell populations in adult periodontitis patients and the effect of periodontal treatment. J Periodontol. 2000;71:1535-1545.

20. Thammasitboon K, Goldring SR, Boch JA. Role of macrophages in LPS-induced osteoblast and PDL cell apoptosis. Bone. 2006;38: $845-852$.

21. Kumada H, Haishima Y, Umemoto T, et al. Structural study on the free lipid A isolated from lipopolysaccharide of Porphyromonas gingivalis. J Bacteriol. 1995;177:2098-2106.

22. Yoshimura A, Hara Y, Kaneko T, et al. Secretion of IL-1 beta, TNFalpha, IL-8 and IL-1 alpha by human polymorphonuclear leukocytes in response to lipopolysaccharides from periodontopathic bacteria. J Periodontal Res. 1997;32:279-286.

23. Vandekerckhove BN, Quirynen M, van Steenberghe D. The use of locally-delivered minocycline in the treatment of chronic periodontitis. A review of the literature. J Clin Periodontol. 1998;25:964-968.

24. Zink MC, Uhrlaub J, DeWitt J, et al. Neuroprotective and anti-human immunodeficiency virus activity of minocycline. JAMA. 2005;293: 2003-2011.

25. Que RP, Liu XF, Qian QF, et al. A clinical study of periocline on the treatment of severe chronic periodontitis. Shanghai Kou Qiang Yi Xue. $2005 ; 14: 257-259$.

26. Torchilin VP. Recent advances with liposomes as pharmaceutical carriers. Nat Rev Drug Discov. 2005;4:145-160.

27. Samad A, Sultana Y, Aqil M. Liposomal drug delivery systems: an update review. Curr Drug Deliv. 2007;4:297-305.

28. Jesorka A, Orwar O. Liposomes: technologies and analytical applications. Ann Rev Anal Chem. 2008;1:801-832.

29. Basha G, Nonobrantseva TI, Rosin N, et al. Influence of cationic lipid composition on gene silencing properties of lipid nanoparticle formulations of siRNA in antigen-presenting cells. Mol Ther. 2011;19: 2186-2200.

30. Reddy KR. Controlled-release, pegylation, liposomal formulations: new mechanisms in the delivery of injectable drugs. J Membrane Sci. 1997; 127:223-227.

31. Mandal TK. Swelling-controlled release system for the vagina delivery of miconazole. Eur J Pharm Biopharm. 2000;50:337-343.

32. Jantzen GM, Robinson JR. Sustained and controlled-release drug delivery systems. In: Banker GS, Rhodes CT, editors. Modern Pharmaceutics. New York, NY: Marcel Dekker, Inc; 2002:501-528.

33. Lu Z, Chen W, Hamman JH. Chitosan-polycarbophil interpolyelectrolyte complex as a matrix former for controlled release of poorly watersoluble drugs I: in vitro evaluation. Drug Dev Ind Pharm. 2010;36: 539-546.

34. Matsuo H, Wakasugi M, Takanaga H, et al. Possibility of the reversal of multidrug resistance and the avoidance of side effects by liposomes modified with MRK-16, a monoclonal antibody to P-glycoprotein J Control Release. 2011;77:77-86.

35. Nobili S, Landini I, Giglioni B, et al. Pharmacological strategies for overcoming multidrug resistance. Curr Drug Targets. 2006;7: $861-879$.
International Journal of Nanomedicine

\section{Publish your work in this journal}

The International Journal of Nanomedicine is an international, peerreviewed journal focusing on the application of nanotechnology in diagnostics, therapeutics, and drug delivery systems throughout the biomedical field. This journal is indexed on PubMed Central,

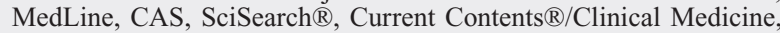

\section{Dovepress}

Journal Citation Reports/Science Edition, EMBase, Scopus and the Elsevier Bibliographic databases. The manuscript management system is completely online and includes a very quick and fair peer-review system, which is all easy to use. Visit http://www.dovepress.com/ testimonials.php to read real quotes from published authors. 